\title{
Sanguinarine-induced apoptosis in lung adenocarcinoma cells is dependent on reactive oxygen species production and endoplasmic reticulum stress
}

\author{
SHUANG GU ${ }^{1,3^{*}}$, XIAO-CHUN YANG ${ }^{2 *}$, XI-YAN XIANG ${ }^{2}$, YAO WU $^{2}$, YU ZHANG $^{2}$, XIAO-YU YAN ${ }^{2}$, \\ YA-NAN XUE ${ }^{2}$, LIAN-KUN SUN ${ }^{2}$ and GUO-GUANG SHAO ${ }^{1}$ \\ ${ }^{1}$ Department of Thoracic Surgery, First Hospital, Jilin University; ${ }^{2}$ Department of Pathophysiology, Basic College of \\ Medicine, Jilin University; ${ }^{3}$ Department of Thoracic Surgery, Jilin Province Hospital, Changchun, Jilin 130021, P.R. China
}

Received April 7, 2015; Accepted April 30, 2015

DOI: $10.3892 /$ or.2015.4054

\begin{abstract}
Sanguinarine (SAN), an alkaloid isolated from plants of the Papaveraceae family, is a compound with multiple biological activities. In the present study, we explored the anticancer properties of SAN in lung cancer using the human lung adenocarcinoma cell line SPC-A1. Our results revealed that SAN inhibited SPC-A1 cell growth and induced apoptosis in a dose-dependent manner. We found that SAN triggered reactive oxygen species (ROS) production, while elimination of ROS by N-acetylcysteine (NAC) reversed the growth inhibition and apoptosis induced by SAN. SAN-induced endoplasmic reticulum (ER) stress resulted in the upregulation of many genes and proteins involved in the unfolded protein response (UPR) pathway, including glucose-regulated protein 78 (GRP78), p-protein kinase R (PKR)-like ER kinase (PERK), p-eukaryotic translation initiation factor $2 \alpha$ (eIF2 $\alpha$ ), activating transcription factor 4 (ATF4) and CCAAT/enhancer binding protein homologous protein (CHOP). Blocking ER stress with tauroursodeoxycholic acid (TUDCA) markedly reduced SAN-induced inhibition of growth and apoptosis. Furthermore, TUDCA decreased SAN-induced ROS production, and NAC attenuated SAN-induced GRP78 and CHOP expression. Overall, our data indicate that the anticancer effects of SAN in lung cancer cells depend on ROS production
\end{abstract}

Correspondence to: Dr Lian-Kun Sun, Department of Pathophysiology, Basic College of Medicine, Jilin University, 126 Xinmin Street, Changchun, Jilin 130021, P.R. China

E-mail: sunlk@jlu.edu.cn

Dr Guo-Guang Shao, Department of Thoracic Surgery, First Hospital, Jilin University, 71 Xinmin Street, Changchun, Jilin 130021, P.R. China E-mail: shaoguoguang520@163.com

\section{${ }^{*}$ Contributed equally}

Key words: sanguinarine, apoptosis, reactive oxygen species, endoplasmic reticulum stress, lung adenocarcinoma and ER stress and that SAN may be a potential agent against lung cancer.

\section{Introduction}

Although significant progress has been made in lung cancer therapy in the past two decades, lung cancer is still the most commonly diagnosed type of cancer (1). In addition, lung cancer is the leading cause of cancer-related mortality, with more than 1,600,000 new cases diagnosed and more than 1,370,000 deaths since 2008 worldwide, with non-small cell lung cancer (NSCLC) accounting for the majority $(1,2)$. Cisplatin-based combination chemotherapy is the most common strategy used to treat advanced NSCLC. Unfortunately, drug resistance has become the main cause of chemotherapy failure (3). Therefore, developing new agents for NSCLC is critical.

Natural products from medicinal plants are important candidates for anticancer agents. For example, pactaxel is found in Taxus brevifolia and vincristine is found in Catharanthus roseus, both of which have been applied as multiple cancer chemotherapies $(4,5)$. Sanguinarine (SAN) is an alkaloid isolated from plants of the Papaveraceae family (6). Previous studies have shown that SAN has antibacterial and antiinflammatory properties (7-9), and recently, SAN has been shown to inhibit cell growth and induce apoptosis in prostate cancer (10), breast cancer (11), cervical cancer (12) and osteosarcomas (13), indicating an anticancer effect. However, the effects of SAN on lung adenocarcinomas remain unclear, and the underlying mechanisms remain to be clarified (14).

Reactive oxygen species (ROS) have multiple functions and play an important role in determining cell fate (15). Many chemotherapy agents depend on the generation of ROS to induce cell death $(16,17)$. Indeed, ROS have become an anticancer target. Studies reveal that drugs promote cell death by activating endoplasmic reticulum (ER) stress-induced signaling pathways, and that triggering ER stress can be an anticancer strategy (18-20). However, ROS production may be the result of ER stress (21-23), and ER stress may be the result of ROS production $(24,25)$. Taken together, the role of ROS and ER stress in cell fate decision has become an area of interest. 
In the present study, we determined the anticancer effects of SAN in lung cancer using the human lung adenocarcinoma cell line SPC-A1, and investigated whether ROS production and ER stress are involved in cell fate decision.

\section{Materials and methods}

Reagents and antibodies. SAN was supplied by Professor Chao-Sheng Li (Institute of Resource, Jilin Academy of Chinese Medicine Sciences, Changchun, China) and dissolved in dimethyl sulfoxide (DMSO). Fetal bovine serum (FBS) and Roswell Park Memorial Institute (RPMI)-1640 culture medium were purchased from Invitrogen (Carlsbad, CA, USA). 3-(4,5-Dimethylthiazol-2-yl)-2,5-diphenyltetrazolium bromide (MTT), tauroursodeoxycholic acid (TUDCA), $\mathrm{N}$-acetylcysteine (NAC) and Hoechst 33258 were purchased from Sigma (St. Louis, MO, USA). The ROS indicator 5-(and -6)-chloromethyl-2',7'-dichlorodihydrofluorescein diacetate acetyl ester (CM- $\mathrm{H}_{2}$ DCFDA) was purchased from Molecular Probes (Eugene, OR, USA). Enhanced chemiluminescence (ECL) reagents were from Thermo Scientific (Rockford, IL, USA). Anti-CCAAT/enhancer binding protein homologous protein (CHOP), anti-glucose-regulated protein 78 (GRP78), anti-p-protein kinase R (PKR)-like ER kinase (PERK), anti-p-eukaryotic translation initiation factor $2 \alpha(\mathrm{eIF} 2 \alpha)$, anti-activating transcription factor 4 (ATF4), anti-Bax and anti-caspase-3 antibodies were purchased from Santa Cruz Biotechnology (Santa Cruz, CA, USA), and anti- $\beta$-actin and horseradish peroxidase-conjugated anti-rabbit and anti-mouse immunoglobulin were purchased from Proteintech (Chicago, IL, USA). All reagents and antibodies were purchased from the Changchun Baoxin Biotechnology Company (Changchun, China).

Cell culture. Human lung adenocarcinoma SPC-A1 cells were obtained from the Chinese Academy of Medical Sciences and Peking Union Medical College. Cell lines were cultured at $37^{\circ} \mathrm{C}$ in $5 \%(\mathrm{v} / \mathrm{v}) \mathrm{CO}_{2}$ in RPMI-1640 culture medium supplemented with $10 \%$ (v/v) FBS. Media were changed at 2-day intervals, and cells were split twice a week by trypsinization. All experiments were performed when cells reached $70 \%$ confluency.

Cell viability assays. The cells were plated in 96-well plates at a density of $1 \times 10^{4}$ cells/well in $200 \mu \mathrm{l}$ of complete medium. Each treatment was repeated in 6 separate wells. The cells were treated as indicated for $24 \mathrm{~h}$, after which $20 \mu \mathrm{l}$ of $5 \mathrm{mg} /$ $\mathrm{ml}$ MTT reagent in phosphate-buffered saline (PBS) was added to each well and incubated for $4 \mathrm{~h}$. Formazan crystals were dissolved in $150 \mu \mathrm{l}$ DMSO. Absorbance was recorded at a wavelength of $490 \mathrm{~nm}$ using a microplate reader (Bio-Rad, Hercules, CA, USA). Cell viability was calculated as: Viability $(\%)=$ absorbance of experimental group/absorbance of control group x $100 \%$. In each experiment, we calculated the mean value of 6 wells/treatment group.

Apoptosis analysis by Hoechst 33258 staining. Apoptotic morphological alterations in nuclear chromatin were detected by Hoechst 33258 staining. Briefly, the SPC-A1 cells were cultured in 24-well plates and treated as indicated for $24 \mathrm{~h}$. The cells were washed with ice-cold PBS and fixed with $4 \%(\mathrm{w} / \mathrm{v})$ paraformaldehyde overnight. The plates were then incubated with $10 \mu \mathrm{M}$ Hoechst 33258 staining solution for $10 \mathrm{~min}$. The cells were visualized under a fluorescence microscope (IX-71; Olympus).

$R T^{2}$ Profiler PCR Array system. The Human Unfolded Protein Response RT ${ }^{2}$ Profiler ${ }^{\mathrm{TM}}$ PCR Array (SABiosciences, Qiagen, Chicago, IL, USA) profiles the expression of 84 key genes involved in unfolded protein accumulation in the ER. Total cellular RNA was extracted from the cultured cells according to the manufacturer's instructions. Single-stranded cDNA was obtained by reverse transcription of $1 \mu \mathrm{g}$ of total RNA using the SABiosciences RT ${ }^{2}$ First Strand kit (SABiosciences). Real-time qPCRs were performed using Applied Biosystems 7300 Fast with SYBR-Green Fluorophore. The reactions were carried out using the $\mathrm{RT}^{2}$ SYBR-Green Master Mix. cDNA was used as a template and cycling parameters were $95^{\circ} \mathrm{C}$ for $10 \mathrm{~min}$, followed by 40 cycles of $95^{\circ} \mathrm{C}$ for $15 \mathrm{sec}$ and $60^{\circ} \mathrm{C}$ for $1 \mathrm{~min}$. Fluorescence intensities were analyzed using the manufacturer's software, and relative quantification was calculated using the $2^{-\Delta \Delta \mathrm{Ct}}$ method. Change in the expression of the 84 genes was shown by heat imaging. Glyceraldehyde 3-phosphate dehydrogenase (GAPDH) was used as a reference gene.

Western blot analysis. Cells were washed with PBS twice and harvested by scraping into $300 \mu$ lof Radio-Immunoprecipitation Assay (RIPA) lysis buffer. Cell lysates were ultrasonicated for $15 \mathrm{sec}$ on ice and then lysed at $4^{\circ} \mathrm{C}$ for $45 \mathrm{~min}$ and centrifuged at $12,000 \times \mathrm{g}$ for $10 \mathrm{~min}$. Protein concentrations in the supernatants were determined using the Bio-Rad reagent (Bio-Rad, Hercules, CA, USA). Equal amounts of protein samples $(30 \mu \mathrm{g})$ were separated by SDS-polyacrylamide gel electrophoresis in duplicate and blotted onto polyvinylidene fluoride membranes (Millipore, Billerica, MA, USA). Transfer efficiency was assessed with Ponceau staining. The blots were blocked in Tris-buffered saline containing 5\% (w/v) nonfat dry milk and probed with specific primary antibodies overnight at $4^{\circ} \mathrm{C}$. The membranes were washed with PBS-Tween-20 and then incubated with a peroxidase-conjugated secondary antibody for $2 \mathrm{~h}$ at room temperature. Duplicated membranes were probed for $\beta$-actin expression to ensure equal input of cell lysate proteins. The final dilutions and incubation times suggested by the manufacturer were used for each antibody. Immunodetection was performed using the ECL reagents and images were captured using Syngene Bio Imaging (Synoptics, Cambridge, UK).

Detection of ROS production. SPC-A1 cells were seeded onto glass culture slides (BD Biosciences, Bedford, MA, USA) and treated with the indicated drugs. At various time-points, the cells were loaded with $1 \mu \mathrm{M}$ CM- ${ }_{2}$ DCFDA in PBS for $10 \mathrm{~min}$ at $37^{\circ} \mathrm{C}$ in the dark followed by a PBS washing step. DCF-dependent fluorescence was examined by laser-scanning confocal microscopy (FV 1000; Olympus).

Statistical analysis. Results are expressed as the mean \pm standard deviation (SD) of repeated experiments, as indicated in the figure legends. Data are representative of three independent experiments performed in triplicate. Statistical analysis of the data was performed using one-way ANOVA. The Tukey's 

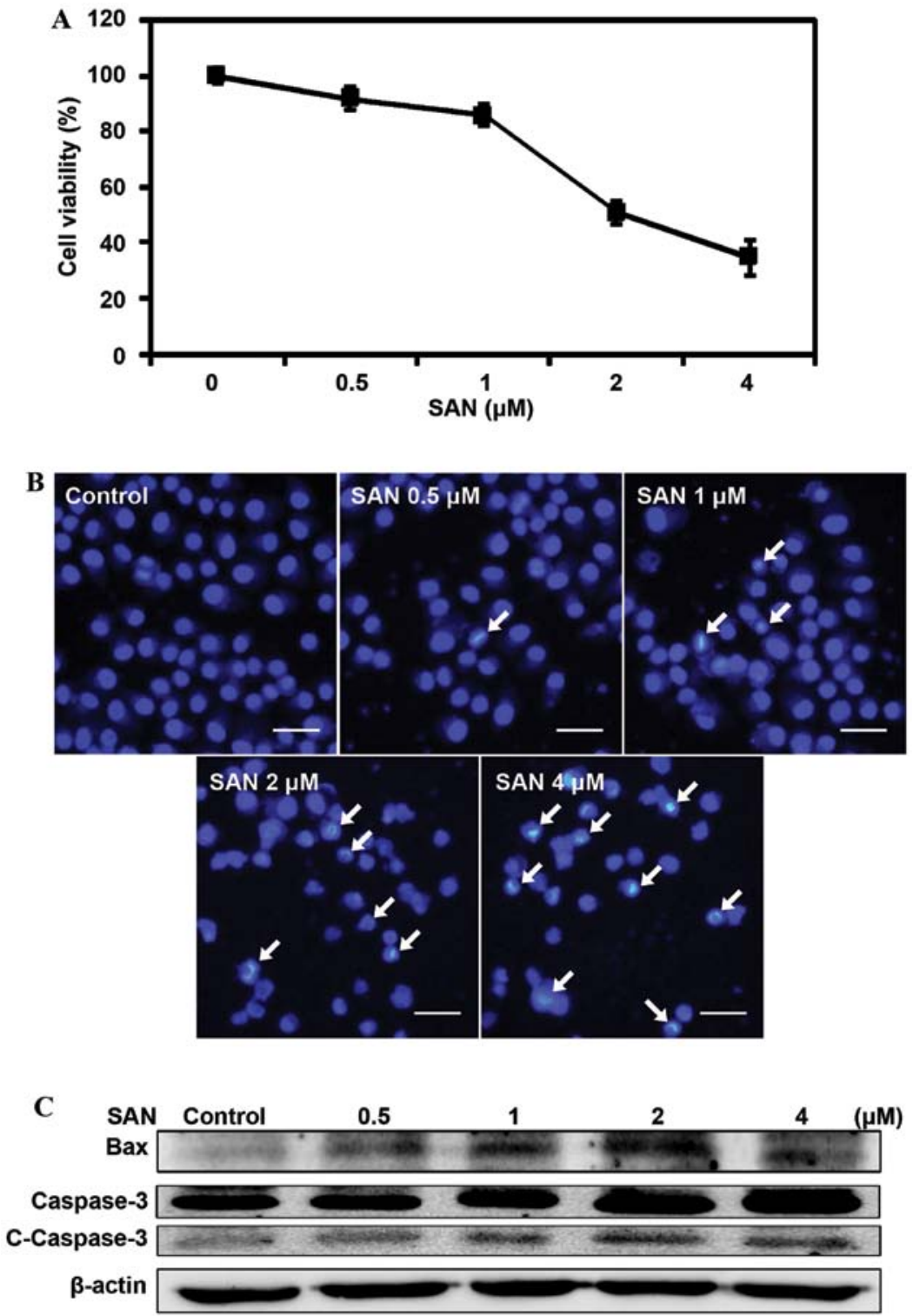

Figure 1. SAN triggers cell growth inhibition and apoptosis in SPC-A1 cells. (A) Effect of SAN on cell viability. Cell viability was detected using the MTT assay. Values represent the mean $\pm \mathrm{SD}(\mathrm{n}=6)$. (B) Effects of SAN on cell apoptosis. Apoptotic cells were stained with Hoechst 33258. Arrows indicate apoptotic cells. Scale bar, $25 \mu \mathrm{m}$. (C) Effect of SAN on Bax and cleaved caspase-3 (C-Caspase-3) protein expression. Cells were treated with different concentrations of SAN $(0,0.5,1,2$ and $4 \mu \mathrm{M})$ for $24 \mathrm{~h}$ in $\mathrm{A}, \mathrm{B}$ and C. SAN, sanguinarine.

post hoc test was used to determine the significance for all pairwise comparisons of interest. Differences were considered statistically significant at $\mathrm{P}<0.05$.

\section{Results}

SAN inhibits the growth and triggers apoptosis in lung cancer cells. To measure the effects of SAN on the growth of lung cancer cells, we treated SPC-A1 cells with different doses $(0.5$, $1,2$ and $4 \mu \mathrm{M})$ of SAN for $24 \mathrm{~h}$ and detected cell viability using the MTT assay. The results revealed that treatment with SAN inhibited cell growth in a dose-dependent manner (Fig. 1A). To investigate whether inhibition of cell growth by SAN is related to cell apoptosis, we monitored apoptosis using Hoechst 33258 staining. After treatment with $0.5,1,2$ and $4 \mu \mathrm{M}$ SAN for $24 \mathrm{~h}$, the cells showed obvious features of apoptosis: chromatin condensation and nuclear fragmentation (Fig. 1B). We monitored the expression levels of the pro-apoptotic proteins Bax and cleaved caspase-3 to confirm SAN-induced apoptosis. As shown in Fig. 1C, SAN treatment upregulated the expression of Bax and cleaved caspase-3, suggesting that inhibition of growth by SAN involves apoptosis. Overall, these results indicate an anticancer role of SAN in SPC-A1 cells.

$S A N$-induced ROS production is involved in the regulation of apoptosis. Classically, chemotherapeutic agent-induced apoptosis was thought to be associated with ROS production $(24,26,22)$. In the present study, we aimed to determine whether ROS were involved in SAN-induced SPC-A1 cell death. After treatment with 1 and $2 \mu \mathrm{M}$ SAN for $24 \mathrm{~h}$, ROS production was detected using $\mathrm{CM}-\mathrm{H}_{2}$ DCFDA staining and laser-scanning confocal microscopy. The results showed that ROS were significantly elevated in a dose-dependent manner (Fig. 2A). ROS production is closely related to 


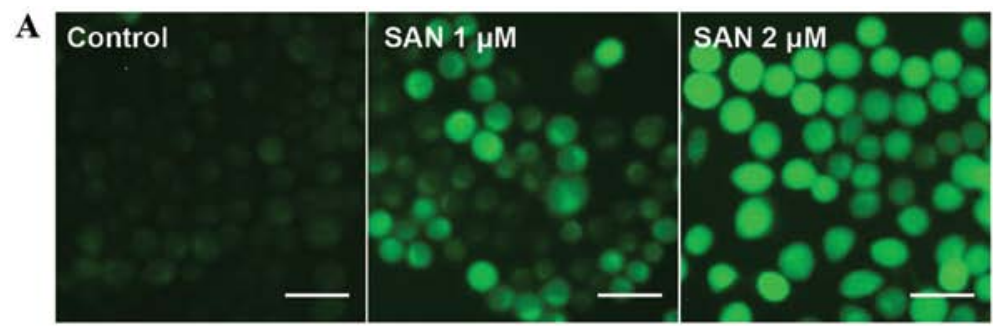

B
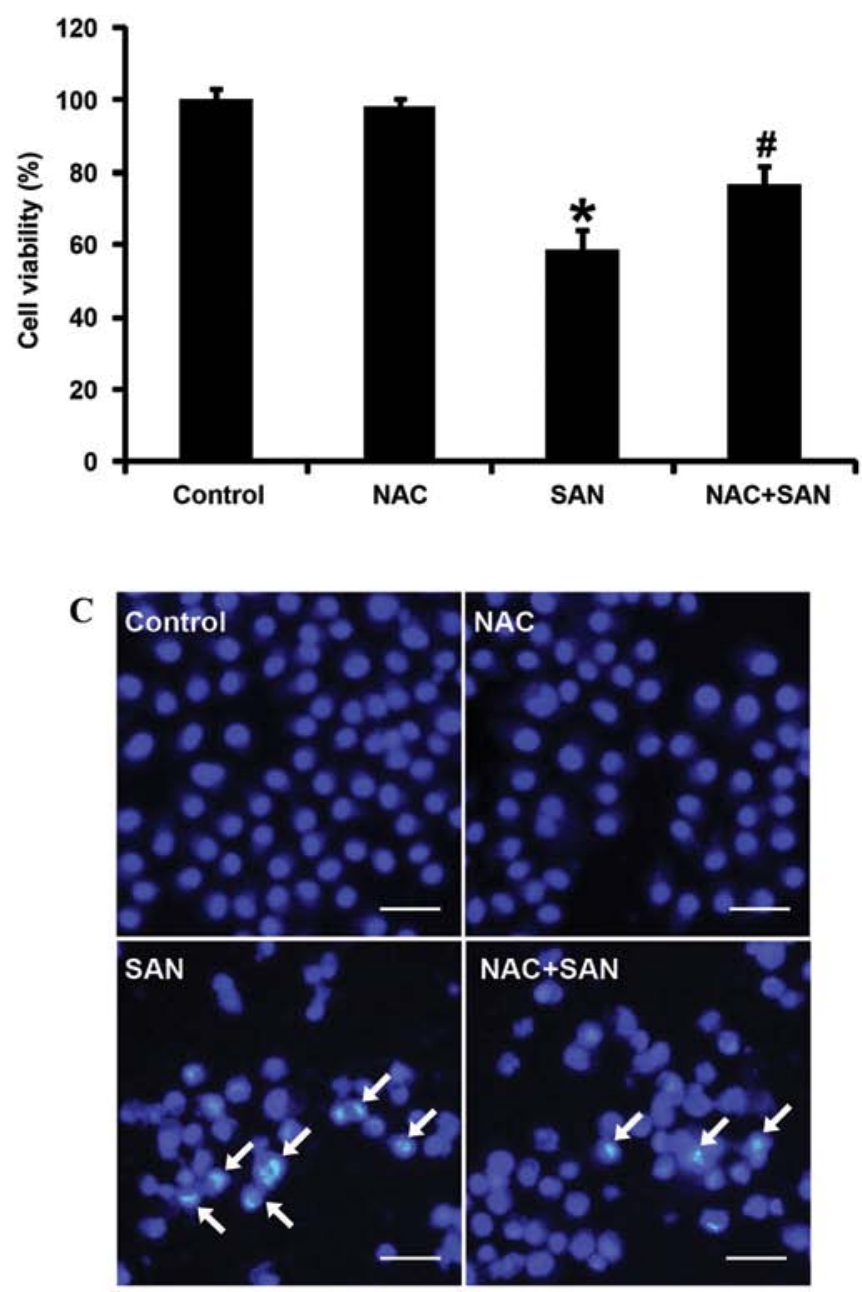

Figure 2. SAN stimulates ROS generation. (A) Effects of SAN on intracellular ROS levels. Cells were treated with SAN (1 and $2 \mu \mathrm{M})$ for $24 \mathrm{~h}$. ROS levels were measured using CM- $\mathrm{H}_{2}$ DCFDA. Scale bar, $25 \mu \mathrm{m}$. (B) Effects of ROS on cell growth inhibition induced by SAN. Treatment groups: $100 \mu \mathrm{M}$ NAC, $2 \mu \mathrm{M}$ SAN, and $100 \mu \mathrm{M}$ NAC plus $2 \mu \mathrm{M}$ SAN for $24 \mathrm{~h}$. Values represent the mean $\pm \mathrm{SD}(\mathrm{n}=6),{ }^{*} \mathrm{P}<0.01$ compared with the control group and ${ }^{\#} \mathrm{P}<0.05$ compared with the SAN group. (C) Effects of SAN on cell apoptosis induced by SAN. Apoptotic cells were stained with Hoechst 33258. Arrows indicate apoptotic cells. Scale bar, $25 \mu \mathrm{m}$. Treatment groups: $100 \mu \mathrm{M} \mathrm{NAC}, 2 \mu \mathrm{M}$ SAN and $100 \mu \mathrm{M}$ NAC plus $2 \mu \mathrm{M}$ SAN for $24 \mathrm{~h}$. SAN, sanguinarine; ROS, reactive oxygen species; NAC, N-acetylcysteine.

the induction of apoptosis. Thus, we investigated whether ROS affect SAN-induced growth inhibition and apoptosis. Pretreatment of SPC-A1 cells with the ROS scavenger (NAC, $100 \mu \mathrm{M}$ for $1 \mathrm{~h}$ ) significantly reversed growth inhibition (Fig. 2B) and apoptosis (Fig. 2C) induced by SAN $(2 \mu \mathrm{M}$ for $24 \mathrm{~h}$ ). Therefore, these results suggest that SAN-mediated growth inhibition and apoptosis partially rely on the generation of ROS.

$S A N$-induced ER stress is involved in the regulation of apoptosis. ROS trigger oxidative stress, which may lead to ER stress through the accumulation of unfolded proteins and/or misfolded proteins. ER stress triggers the unfolded protein response (UPR), which involves a great variety of molecules. We monitored changes in the expression of genes associated with the UPR pathway using the PCR array assay. The results showed that 32 genes were upregulated more than 2-fold after treatment with SAN ( $2 \mu \mathrm{M}$ for $24 \mathrm{~h})$ in the SPC-A1 cells, including glucose-regulated protein 78 (GRP78, also called HSPA5, position D4), inositol requiring kinase $1 \alpha$ (IRE1 $\alpha$, also called ERN1, position C2), activating transcription factor $6 \alpha$ (ATF6 $\alpha$, position A3), activating transcription factor 4 (ATF4, position A2), growth arrest and DNA-damage-inducible gene 34 (GADD34, also called PPP1R15A, position E11) and 
A

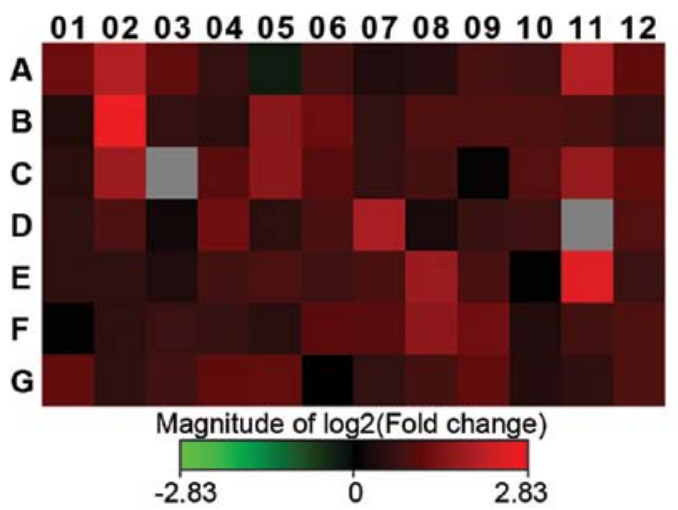

C

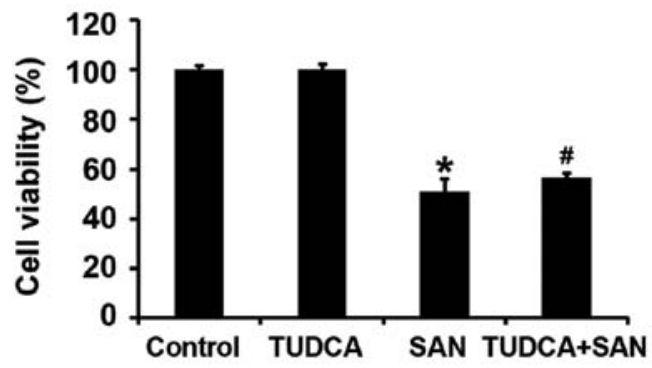

B

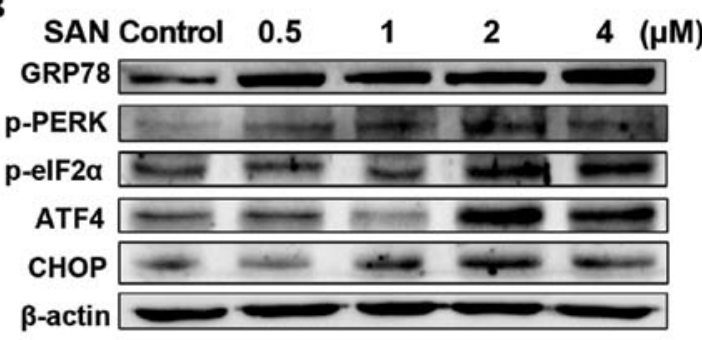

D
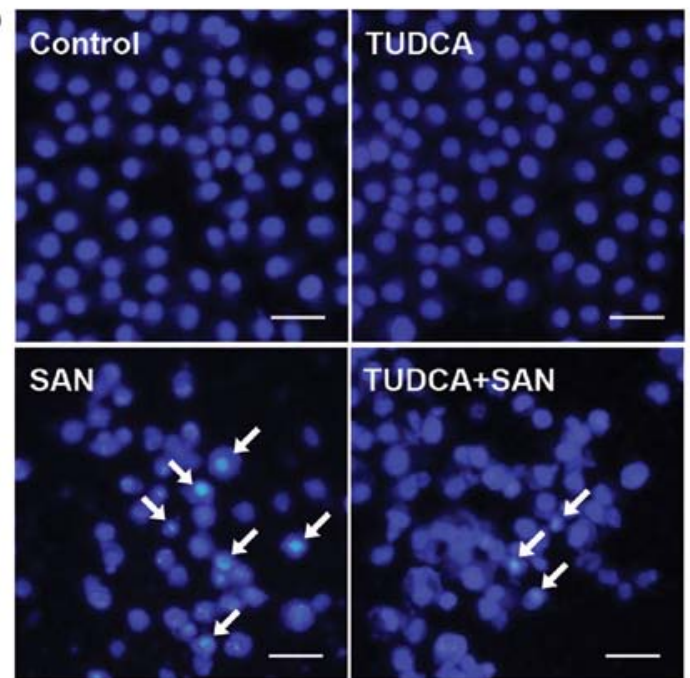

Figure 3. SAN induces ER stress. (A) Expression of UPR pathway genes. SPC-A1 cells were incubated with $2 \mu \mathrm{M}$ SAN for 24 h. Changes in gene expression levels were detected using the PCR array assay. Red, upregulation; green, downregulation. Gene details not shown. (B) Effects of SAN on ER stress-related proteins. The protein expression levels of GRP78, p-PERK, p-eIF2 $\alpha$, ATF4 and CHOP were detected by western blotting. Cells were treated with different concentrations of SAN $(0,0.5,1,2$ and $4 \mu \mathrm{M})$ for $24 \mathrm{~h}$. (C) Effects of TUDCA on SAN-induced cell growth inhibition. Treatment groups: $50 \mu \mathrm{M}$ TUDCA, $2 \mu \mathrm{M} \mathrm{SAN}$, and $50 \mu \mathrm{M}$ TUDCA plus $2 \mu \mathrm{M}$ SAN for $24 \mathrm{~h}$. Values represent the mean $\pm \mathrm{SD}(\mathrm{n}=6),{ }^{*} \mathrm{P}<0.01$ compared with the control group, ${ }^{\#} \mathrm{P}<0.05$ compared with the SAN group. (D) Effects of TUDCA on SAN-induced apoptosis. Apoptotic cells were stained with Hoechst 33258 . Treatment groups: $50 \mu$ M TUDCA, $2 \mu \mathrm{M} \mathrm{SAN}$, and $50 \mu \mathrm{M}$ TUDCA plus $2 \mu \mathrm{M}$ SAN for $24 \mathrm{~h}$. Arrows indicate apoptotic cells. Scale bar, $25 \mu \mathrm{m}$. SAN, sanguinarine; UPR, unfolded protein response; ER, endoplasmic reticulum; TUDCA, tauroursodeoxycholic acid.

CAAT/enhancer binding protein homologous protein $(\mathrm{CHOP}$, also called DDIT3, position B2) (Fig. 3A). We next confirmed ER stress by measuring protein expression by western blotting. Consistently, the expression of GRP78, p-protein kinase R (PKR)-like ER kinase (p-PERK), p-eukaryotic translation initiation factor $2 \alpha$ (p-elF2 $\alpha$ ), ATF4 and CHOP were significantly increased in a dose-dependent manner (Fig. 3B). Therefore, SAN can induce ER stress in SPC-A1 cells.

ER stress is thought to play an important role in the cell pathophysiology process associated with cell death (27). To confirm the effects of ER stress on SAN-induced growth inhibition, we blocked ER stress using $50 \mu \mathrm{M}$ TUDCA for $1 \mathrm{~h}$, followed by treatment with $2 \mu \mathrm{M}$ SAN for $24 \mathrm{~h}$, and then detected cell viability using the MTT assay. Results indicated that TUDCA partly reversed SAN-induced cell growth inhibition (Fig. 3C). In addition, the Hoechst 33258 staining assay showed similar results, with TUDCA inhibiting SAN-induced apoptosis (Fig. 3D). These data suggest that ER stress is associated with $\mathrm{SAN}$-induced cell growth inhibition and apoptosis in SPC-A1 cells.

Relationship between ER stress and ROS in lung cancer cells. To investigate the relationship between ER stress and ROS, we aimed to determine whether ER stress is involved in the regulation of ROS production. Notably, pretreatment with $50 \mu \mathrm{M}$ TUDCA for $1 \mathrm{~h}$, followed by treatment with $2 \mu \mathrm{M}$ SAN for $24 \mathrm{~h}$, partially reversed SAN-induced ROS production (Fig. 4A). Next, the expression of the ER stress-related proteins GRP78 and CHOP were monitored after blocking ROS with NAC. After pretreatment of SPC-A1 cells with $100 \mu \mathrm{M}$ NAC for $1 \mathrm{~h}$, followed by treatment with $2 \mu \mathrm{M}$ SAN for $24 \mathrm{~h}$, SAN-induced expression of GRP78 and CHOP was markedly attenuated (Fig. 4B). These data suggest that blocking ER stress with TUDCA can reduce ROS production, whereas eliminating ROS by NAC can attenuate the extent of ER stress. Therefore, ER stress and ROS production promote each other and form a vicious cycle.

\section{Discussion}

Chemotherapy resistance is an important cause of treatment failure in lung cancer. Therefore, identifying new and effective agents is of particular importance (28). In the present study, we investigated the anticancer effects and mechanism of action of SAN in lung adenocarcinoma cells. We found that: i) SAN inhibit cell growth in the human lung adenocarcinoma cell line 
A
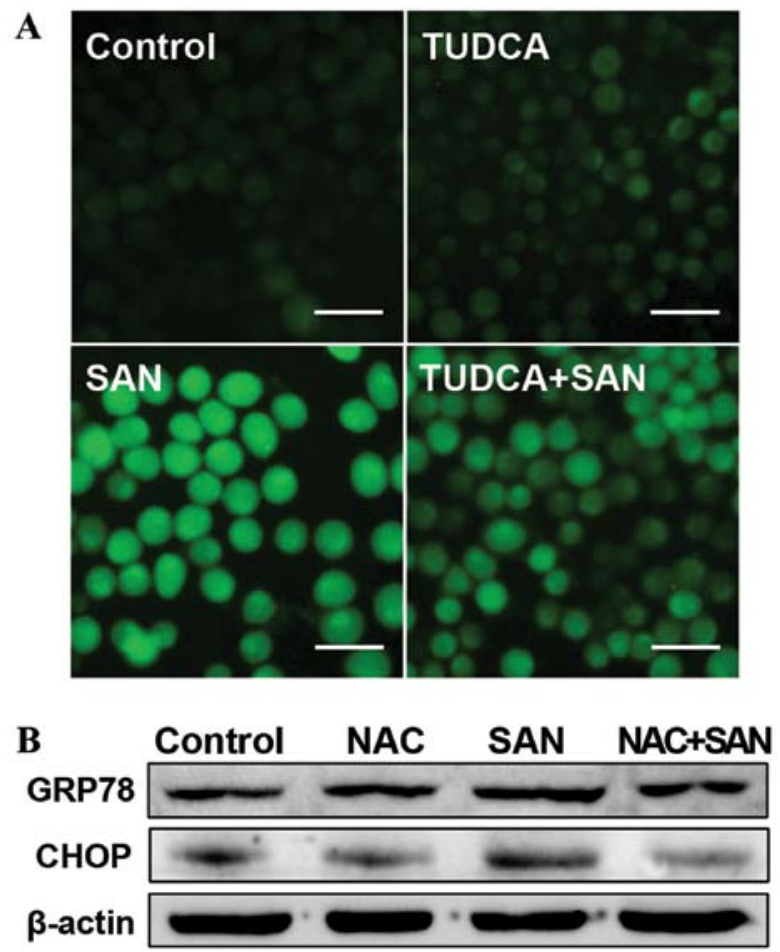

Figure 4. Relationship between ER stress and ROS in SPC-A1 cells. (A) Effects of TUDCA on ROS generation. Cells were treated with $50 \mu \mathrm{M}$ TUDCA, $2 \mu \mathrm{M}$ SAN, and $50 \mu \mathrm{M}$ TUDCA plus $2 \mu \mathrm{M}$ SAN for $24 \mathrm{~h}$. Bar: $25 \mu \mathrm{m}$. (B) Effects of NAC on SAN-induced ER stress. The protein expression levels of GRP78 and CHOP were detected by western blotting. Treatment groups: $100 \mu \mathrm{M}$ NAC, $2 \mu \mathrm{M}$ SAN and $100 \mu \mathrm{M}$ NAC plus $2 \mu \mathrm{M} \mathrm{SAN}$ for $24 \mathrm{~h}$. SAN, sanguinarine; ER, endoplasmic reticulum; TUDCA, tauroursodeoxycholic acid; ROS, reactive oxygen species; NAC, N-acetylcysteine.

SPC-A1 and induce apoptosis in a dose-dependent manner; ii) SAN triggered the generation of ROS, and eliminating ROS led to marked downregulation of SAN-induced growth inhibition and apoptosis; iii) SAN activated the ER stress signaling pathway, and blocking ER stress markedly attenuated SAN-induced growth inhibition and apoptosis; and iv) inhibition of ER stress can decrease ROS production, whereas inhibition of ROS production can decrease the extent of ER stress.

SAN is a benzophenanthridine alkaloid found in several plants of the Papaveraceae family, including Chelidonium majus, Bocconia frutescens and Sanguinaria canadensis. Studies have demonstrated that SAN has anticancer effects in various types of cancer, including prostate cancer, osteosarcomas, breast cancer and colorectal cancer $(10,13,29,30)$. In the present study, SAN decreased cell viability in a dose-dependent manner in the human lung adenocarcinoma cell line SPC-A1. Meanwhile, we observed a dose-related induction of apoptosis, indicating that SAN-induced growth inhibition involved apoptosis. This evidence suggests that SAN may be a potential chemotherapeutic candidate for lung cancer.

The most common forms of ROS, including superoxide, $\mathrm{H}_{2} \mathrm{O}_{2}$ and hydroxyl radicals, are primarily generated during respiratory ATP synthesis in mitochondria (31). ROS are involved in a variety of cell signaling processes and have a vital role in the execution of cell physiological function. However, accumulation of excessive intercellular ROS can trigger oxidative stress, leading to apoptosis (32). A previous study showed that SAN induced apoptosis in the human colorectal cancer cell line HCT-116 through generation of ROS, followed by mitochondrial membrane potential collapse (30). Thus, we examined whether SAN-induced growth inhibition and apoptosis were dependent on ROS production in lung cancer cell line. Our results showed that SAN triggered a dose-dependent generation of ROS. Importantly, eliminating ROS using NAC decreased ROS production, and attenuated SAN-induced growth inhibition and apoptosis. These data suggest that SAN induces an anticancer effect that is partially dependent on ROS production.

The ER is involved in secretion and membrane-targeted protein folding and modification. Abnormal conditions such as oxidative stress, nutrient deprivation and disruption of $\mathrm{Ca}^{2+}$ homeostasis can lead to misfolded and/or unfolded protein accumulation in the lumen of the ER, followed by activation of the ER stress response-UPR $(20,27,33)$. There are three sensors of ER stress: IRE1, PERK and ATF6, which are responsible for initiation of UPR signaling (34). The UPR attenuates ER stress by decreasing general protein translation, promoting the protein folding capacity of the ER or by enhancing ER-associated degradation (35). However, recovery from severe ER stress is difficult and it triggers apoptosis through activation of CHOP, a pro-apoptotic transcription factor involved in all three arms of UPR signaling (36-38). Many studies have found that ER stress is involved in the response of cancer cells to chemotherapeutic agents (39-41). In the present study, SAN triggered ER stress, which resulted in the regulation of growth inhibition and apoptosis in lung cancer SPC-A1 cells. We found that: i) SAN upregulated the expression of 32 genes involved in the UPR pathway; ii) SAN increased the expression of ER stress-related proteins, including GRP78, p-PERK, p-elF2 $\alpha$, ATF4 and CHOP; and iii) blocking ER stress with TUDCA markedly decreased SAN-induced growth inhibition and apoptosis. Therefore, these results indicate that $\mathrm{SAN}$-induced growth inhibition and apoptosis partially depend on ER stress.

Numerous studies have shown that ER stress is associated with oxidative stress. High levels of ROS can induce the accumulation of misfolded and/or unfolded proteins in the ER and lead to ER stress $(20,24)$, whereas continuous ER stress can promote ROS production $(21,26)$. Our study showed that SAN increased ROS production, and that blocking ER stress using TUDCA decreased SAN-induced ROS production. Notably, eliminating ROS with NAC markedly decreased the expression of ER stress-associated proteins GRP78 and CHOP. These data indicate that ROS production and ER stress are mutually essential and form a vicious cycle (22).

Collectively, we demonstrated that SAN induced cell growth inhibition and apoptosis in lung adenocarcinoma SPC-A1 cells, and that these effects were partly dependent on ROS production and ER stress. Our findings may be useful for the development of SAN as an anticancer agent for lung cancer. However, the anticancer effects in vivo and the precise mechanism of action of SAN require further investigation.

\section{Acknowledgements}

This study was supported by the National Natural Science Foundation of China (no. 81272876) and the Development of Science and Technology Plan Projects of Jilin (no. 2012Z019). 


\section{References}

1. Jemal A, Bray F, Center MM, Ferlay J, Ward E and Forman D Global cancer statistics. CA Cancer J Clin 61: 69-90, 2011.

2. Klastersky J and Awada A: Milestones in the use of chemotherapy for the management of non-small cell lung cancer (NSCLC). Crit Rev Oncol Hematol 81: 49-57, 2012.

3. Wang G, Reed E and Li QQ: Molecular basis of cellular response to cisplatin chemotherapy in non-small cell lung cancer (Review). Oncol Rep 12: 955-965, 2004. (Review).

4. de Weger VA, Beijnen JH and Schellens JHM: Cellular and clinical pharmacology of the taxanes docetaxel and paclitaxel - a review. Anticancer Drugs 25: 488-494, 2014.

5. Wang L, Wei D, Han X, Zhang W, Fan C, Zhang J, Mo C, Yang M, Li J, Wang Z, et al: The combinational effect of vincristine and berberine on growth inhibition and apoptosis induction in hepatoma cells. J Cell Biochem 115: 721-730, 2014.

6. Sun M, Lou W, Chun JY, Cho DS, Nadiminty N, Evans CP, Chen J, Yue J, Zhou Q and Gao AC: Sanguinarine suppresses prostate tumor growth and inhibits survivin expression. Genes Cancer 1: 283-292, 2010.

7. Godowski KC: Antimicrobial action of sanguinarine. J Clin Dent 1: 96-101, 1989.

8. Eisenberg AD, Young DA, Fan-Hsu J and Spitz LM: Interactions of sanguinarine and zinc on oral streptococci and Actinomyces species. Caries Res 25: 185-190, 1991.

9. Chaturvedi MM, Kumar A, Darnay BG, Chainy GB, Agarwal S and Aggarwal BB: Sanguinarine (pseudochelerythrine) is a potent inhibitor of NF- $\kappa \mathrm{B}$ activation, I $\mathrm{B} \alpha$ phosphorylation, and degradation. J Biol Chem 272: 30129-30134, 1997.

10. Adhami VM, Aziz MH, Reagan-Shaw SR, Nihal M, Mukhtar H and Ahmad N: Sanguinarine causes cell cycle blockade and apoptosis of human prostate carcinoma cells via modulation of cyclin kinase inhibitor-cyclin-cyclin-dependent kinase machinery. Mol Cancer Ther 3: 933-940, 2004

11. Park SY, Jin ML, Kim YH, Lee S-J and Park G: Sanguinarine inhibits invasiveness and the MMP-9 and COX-2 expression in TPA-induced breast cancer cells by inducing HO-1 expression. Oncol Rep 31: 497-504, 2014.

12. Xu JY, Meng QH, Chong Y, Jiao Y, Zhao L, Rosen EM and Fan S Sanguinarine inhibits growth of human cervical cancer cells through the induction of apoptosis. Oncol Rep 28: 2264-2270, 2012.

13. Park H, Bergeron E, Senta H, Guillemette K, Beauvais S, Blouin R, Sirois $\mathbf{J}$ and Faucheux N: Sanguinarine induces apoptosis of human osteosarcoma cells through the extrinsic and intrinsic pathways. Biochem Biophys Res Commun 399: 446-451, 2010.

14. Jang BC, Park JG, Song DK, Baek WK, Yoo SK, Jung KH, Park GY, Lee TY and Suh SI: Sanguinarine induces apoptosis in A549 human lung cancer cells primarily via cellular glutathione depletion. Toxicol In Vitro 23: 281-287, 2009.

15. Martínez-Reyes I and Cuezva JM: The H(+)-ATP synthase: A gate to ROS-mediated cell death or cell survival. Biochim Biophys Acta 1837: 1099-1112, 2014.

16. Ding Y, Zhu W, Sun R, Yuan G, Zhang D, Fan Y and Sun J: Diphenylene iodonium interferes with cell cycle progression and induces apoptosis by modulating $\mathrm{NAD}(\mathrm{P}) \mathrm{H}$ oxidase/ROS/cell cycle regulatory pathways in Burkitt's lymphoma cells. Oncol Rep 33: 1434-1442, 2015

17. Ma J, Yang J, Wang C, Zhang N, Dong Y, Wang C, Wang Y and Lin X: Emodin augments cisplatin cytotoxicity in platinum-resistant ovarian cancer cells via ROS-dependent MRP1 downregulation. BioMed Res Int 2014: 107671, 2014.

18. Lim YJ, Choi JA, Lee JH, Choi CH, Kim HJ and Song $\mathrm{CH}$ : Mycobacterium tuberculosis 38-kDa antigen induces endoplasmic reticulum stress-mediated apoptosis via toll-like receptor 2/4. Apoptosis 20: 358-370, 2014.

19. Sanchez-Lopez E, Zimmerman T, Gomez del Pulgar T, Moyer MP, Lacal Sanjuan JC and Cebrian A: Choline kinase inhibition induces exacerbated endoplasmic reticulum stress and triggers apoptosis via CHOP in cancer cells. Cell Death Dis 4 e933, 2013

20. Min KJ, Jung KJ and Kwon TK: Carnosic acid induces apoptosis through reactive oxygen species-mediated endoplasmic reticulum stress induction in human renal carcinoma Caki cells. J Cancer Prev 19: 170-178, 2014

21. Yang X, Xiang X, Xia M, Su J, Wu Y, Shen L, Xu Y and Sun L: Inhibition of JNK 3 promotes apoptosis induced by BH3 mimetic S1 in chemoresistant human ovarian cancer cells. Anat Rec 298: 386-395, 2015.
22. Malhotra JD and Kaufman RJ: Endoplasmic reticulum stress and oxidative stress: a vicious cycle or a double-edged sword? Antioxid Redox Signal 9: 2277-2293, 2007

23. Song B, Scheuner D, Ron D, Pennathur S and Kaufman RJ: Chop deletion reduces oxidative stress, improves $\beta$ cell function, and promotes cell survival in multiple mouse models of diabetes. J Clin Invest 118: 3378-3389, 2008.

24. Boussabbeh M, Salem IB, Prola A, Guilbert A, Bacha H, Abid-Essefi $S$ and Lemaire C: Patulin induces apoptosis through ROS-mediated endoplasmic reticulum stress pathway. Toxicol Sci 144: 328-337, 2015.

25. Muchowicz A, Firczuk M, Wachowska M, Kujawa M, Jankowska-Steifer E, Gabrysiak M, Pilch Z, Kłossowski S, Ostaszewski R and Golab J: SK053 triggers tumor cell apoptosis by oxidative stress-mediated endoplasmic reticulum stress. Biochem Pharmacol 93: 418-427, 2015.

26. He PX, Zhang J, Che YS, He QJ, Chen Y and Ding J: G226, a new epipolythiodioxopiperazine derivative, triggers DNA damage and apoptosis in human cancer cells in vitro via ROS generation. Acta Pharmacol Sin 35: 1546-1555, 2014.

27. Malhotra JD and Kaufman RJ: ER stress and its functional link to mitochondria: Role in cell survival and death. Cold Spring Harb Perspect Biol 3: a004424, 2011.

28. Wang S, Pan H, Liu D, Mao N, Zuo C, Li L, Xie T, Huang D, Huang Y, Pan Q, et al: Excision repair cross complementation group 1 is a chemotherapy-tolerating gene in cisplatin-based treatment for non-small cell lung cancer. Int J Oncol 46: 809-817, 2015.

29. Kalogris C, Garulli C, Pietrella L, Gambini V, Pucciarelli S, Lucci C, Tilio M, Zabaleta ME, Bartolacci C, Andreani C, et al: Sanguinarine suppresses basal-like breast cancer growth through dihydrofolate reductase inhibition. Biochem Pharmacol 90: 226-234, 2014.

30. Han MH, Kim GY, Yoo YH and Choi YH: Sanguinarine induces apoptosis in human colorectal cancer HCT-116 cells through ROS-mediated Egr-1 activation and mitochondrial dysfunction. Toxicol Lett 220: 157-166, 2013.

31. Gupta SC, Hevia D, Patchva S, Park B, Koh W and Aggarwal BB: Upsides and downsides of reactive oxygen species for cancer: the roles of reactive oxygen species in tumorigenesis, prevention, and therapy. Antioxid Redox Signal 16: 1295-1322, 2012.

32. Cairns RA, Harris IS and Mak TW: Regulation of cancer cell metabolism. Nat Rev Cancer 11: 85-95, 2011.

33. Malhotra JD and Kaufman RJ: The endoplasmic reticulum and the unfolded protein response. Semin Cell Dev Biol 18: 716-731, 2007.

34. Oakes SA and Papa FR: The role of endoplasmic reticulum stress in human pathology. Annu Rev Pathol 10: 173-194, 2014.

35. Mollereau B, Manié S and Napoletano F: Getting the better of ER stress. J Cell Commun Signal 8: 311-321, 2014.

36. Dubey $R$ and Saini N: STAT6 silencing up-regulates cholesterol synthesis via miR-197/FOXJ2 axis and induces ER stress-mediated apoptosis in lung cancer cells. Biochim Biophys Acta 1849: 32-43, 2015

37. Jiang T, Wang L, Li X, Song J, Wu X and Zhou S: Inositol-requiring enzyme 1-mediated endoplasmic reticulum stress triggers apoptosis and fibrosis formation in liver cirrhosis rat models. Mol Med Rep 11: 2941-2946, 2015.

38. Feng J, Chen X, Sun X, Wang F and Sun X: Expression of endoplasmic reticulum stress markers GRP78 and CHOP induced by oxidative stress in blue light-mediated damage of A2E-containing retinal pigment epithelium cells. Ophthalmic Res 52: 224-233, 2014.

39. Kang KA, Kim JK, Jeong YJ, Na SY and Hyun JW: Dictyopteris undulata extract induces apoptosis via induction of endoplasmic reticulum stress in human colon cancer cells. J Cancer Prev 19: 118-124, 2014.

40. Wang Y, Alam GN, Ning Y, Visioli F, Dong Z, Nör JE and Polverini PJ: The unfolded protein response induces the angiogenic switch in human tumor cells through the PERK/ATF4 pathway. Cancer Res 72: 5396-5406, 2012.

41. Mimura N, Hideshima T, Shimomura T, Suzuki R, Ohguchi H, Rizq O, Kikuchi S, Yoshida Y, Cottini F, Jakubikova J, et al: Selective and potent Akt inhibition triggers anti-myeloma activities and enhances fatal endoplasmic reticulum stress induced by proteasome inhibition. Cancer Res 74: 4458-4469, 2014. 